\title{
Letters
}

\section{NATIONAL PNEUMOCOCCAL VACCINATION PROGRAMMES FOR CHILDREN IN EUROPE, 2001-2007: UPDATE FROM IRELAND}

\author{
S Cotter (suzanne.cotter@hse.ie) ${ }^{1}$ \\ 1. Health Protection Surveillance Centre, Dublin, Ireland
}

To the editor: With reference to the article by Carvalho Gomes et al. entitled "Use of seven-valent pneumococcal conjugate vaccine (PCV7) in Europe, 2001-2007" (http://www.eurosurveillance. org/ViewArticle.aspx?Articleld=19159), published on 26 March 2009 , I wish to point out that in addition to the introduction of a universal PCV vaccination programme in September 2008, the Health Services Executive of Ireland also organised a PCV7 catch-up programme for children up to the age of 24 months (one or two doses depending on age).

Additionally, since October 2002, PCV7 has been recommended for at risk children up to the age of 24 months. In September 2008, this age group was expanded to include at risk children up to five years of age (one or two doses, depending on age and risk factor).

Recommended vaccines are free for children.

This article was published on 7 May 2009.

Citation style for this article: Cotter S. National pneumococcal vaccination programmes for children in Europe, 2001-2007: update from Ireland. Euro Surveill. 2009;14(18):pij=19201. Available online: http://www.eurosurveillance.org/ViewArticle. aspx?ArticleId $=19201$ 